\title{
Aortic and mitral valve replacement with reconstruction of the intervalvular fibrous body: An analysis of clinical outcomes
}

\author{
Nilto C. De Oliveira, MD \\ Tirone E. David, MD \\ Susan Armstrong, MSc \\ Joan Ivanov, PhD
}

\footnotetext{
From the Division of Cardiovascular Surgery of Toronto General Hospital and University of Toronto, Toronto, Ontario, Canada.

Read at the Thirtieth Annual Meeting of The Western Thoracic Surgical Association, Maui, Hawaii, June 23-26, 2004.

Received for publication July 21, 2004; revisions received Sept 8, 2004; accepted for publication Sept 22, 2004

Address for reprints: Tirone E. David, MD, 200 Elizabeth St, 13EN219, Toronto, Ontario, Canada M5G 2C4 (E-mail: tirone. david@uhn.on.ca).

J Thorac Cardiovasc Surg 2005;129:286-90 $0022-5223 / \$ 30.00$

Copyright (C) 2005 by The American Association for Thoracic Surgery

doi:10.1016/j.jtcvs.2004.09.032
}

Objective: This study was undertaken to evaluate the late outcomes of reconstruction of the intervalvular fibrous body during aortic and mitral valve replacement.

Methods: Seventy-six consecutive patients underwent reconstruction of the intervalvular fibrous body with replacement of the mitral and aortic valves. There were 35 men and 41 women whose mean age was $58 \pm 12$ years. Additional procedures were circumferential reconstruction of the mitral annulus in 27 patients, tricuspid valve repair in 21, coronary artery bypass in 15, and aortic root replacement in 4 . Indications for the operation were active infective endocarditis with abscess in 15 patients, extensive calcification of the mitral annulus and interventricular fibrous body in 24 , lack of fibrous tissue to secure a prosthetic valve in 17 , and treatment or prevention of patient-prosthesis mismatch in 20. Fifty-five patients had undergone one or more previous valve operations, and $52(68 \%)$ were in functional class IV. The mean follow-up was $47 \pm 47$ months, and it was complete.

Results: There were $8(10 \%)$ operative and 18 (24\%) late deaths. The 10-year survival was $50 \% \pm 9 \%$. There were 15 reoperations in 12 patients: 7 for prosthetic valve endocarditis (5 early, 2 late), 7 for patch or valve dehiscence (3 early, 4 late), and 1 for structural valve deterioration. All but 2 reoperations were re-reconstruction of the intervalvular fibrous body and double valve replacement. The 10-year freedom from reoperation was $73 \% \pm 7 \%$.

Conclusion: Reconstruction of the intervalvular fibrous body during double valve replacement is a technically challenging operation, but it is useful in patients with complex valve pathology for whom no alternative procedure is available.

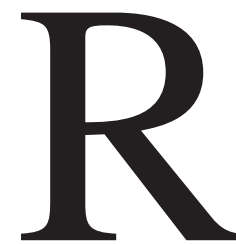

econstruction of the intervalvular fibrous body during aortic and mitral valve replacement may be the only alternative to treat some patients with extensive calcification of the base of the heart, active infective endocarditis with abscess, inadequate intervalvular fibrous tissue to secure a prosthetic valve because of multiple previous operations, or a need to prevent or treat patient-prosthesis mismatch. ${ }^{1-6}$ Glutaraldehyde-fixed bovine pericardium and Dacron polyester fabric have been used as patch materials, with similar early results. ${ }^{1}$ The long-term results of these operations remain unknown. This study is an analysis of the early and late outcomes of reconstruction of the intervalvular fibrous body during aortic and mitral valve replacement.

\section{Patients and Methods}

Between 1985 and 2002, a total of 76 patients underwent reconstruction of the intervalvular fibrous body with replacement of the mitral and aortic valves by a single surgeon. There were 35 men and 41 women, and the mean age was $58 \pm 12$ 


\section{TABLE 1. Operative data}

\begin{tabular}{lc}
\hline Operations performed & \\
Reconstruction of intervalvular fibrous body & $76(100 \%)$ \\
Circumferential reconstruction of mitral annulus & $26(34 \%)$ \\
Aortic root replacement & $4(5 \%)$ \\
Tricuspid valve repair & $21(28 \%)$ \\
$\quad$ Coronary artery bypass grafting & $15(20 \%)$ \\
Patch material & \\
$\quad$ Bovine pericardium & $42(55 \%)$ \\
Dacron fabric & $34(45 \%)$ \\
Prosthetic valves implanted & \\
$\quad$ Mechanical & $49(64 \%)$ \\
Bioprosthetic & $27(36 \%)$ \\
Aortic crossclamp time (min, mean \pm SD) & $127 \pm 27$ \\
Cardiopulmonary bypass time (min, mean \pm SD) & $152 \pm 31$ \\
\hline
\end{tabular}

years (range 26-80 years). The main indications for operation were congestive heart failure in 61 patients $(80 \%)$ and infective endocarditis with aortic root abscess in 15 (20\%). Fifty-two patients (68\%) were in New York Heart Association functional class IV, 19 (25\%) in class III, and 5 (7\%) in class II. Fifty-five patients (72\%) had undergone previous operations, including mitral valve replacement in 47 and aortic valve replacement in 44 . Fourteen (18\%) patients had coronary artery disease. The left ventricular ejection fraction was greater than $60 \%$ in $10(13 \%)$ patients, $41 \%$ to $59 \%$ in $49(54 \%), 20 \%$ to $40 \%$ in $13(17 \%)$, and unknown in 4 $(5 \%)$. Thirty-six $(47 \%)$ patients were operated on electively, $35(47 \%)$ urgently, and $5(6 \%)$ as an emergency.

\section{Operations}

The operative technique has previously been described. ${ }^{1}$ It consisted of extending the aortotomy into the noncoronary aortic sinus, into the intervalvular fibrous body and dome of the left atrium toward the right pulmonary artery, exposing both the left ventricular inflow and outflow tracts. The extensiveness of the resection and reconstruction depended on the pathology. Patients with abscess had more extensive resection. After resection of all infected, calcified, and abnormal tissues, circumferential reconstruction of the mitral annulus was required in cases of posterior annular destruction as a result of abscess in the mitral annulus or extensive degenerative calcification. ${ }^{1,3}$ In these cases, the reconstruction of the mitral annulus was achieved by suturing a large strip of glutaraldehyde bovine pericardium patch to the endocardium of the left ventricle from the lateral to the medial fibrous trigones. Approximately two thirds of the circumference of a prosthetic mitral valve was secured to the patch posteriorly. If the native mitral annulus was free of disease, the prosthetic valve circumference was secured to the native posterior mitral annulus. A double triangular shaped patch of Dacron polyester fabric or bovine pericardium was sutured to the lateral and medial fibrous trigones

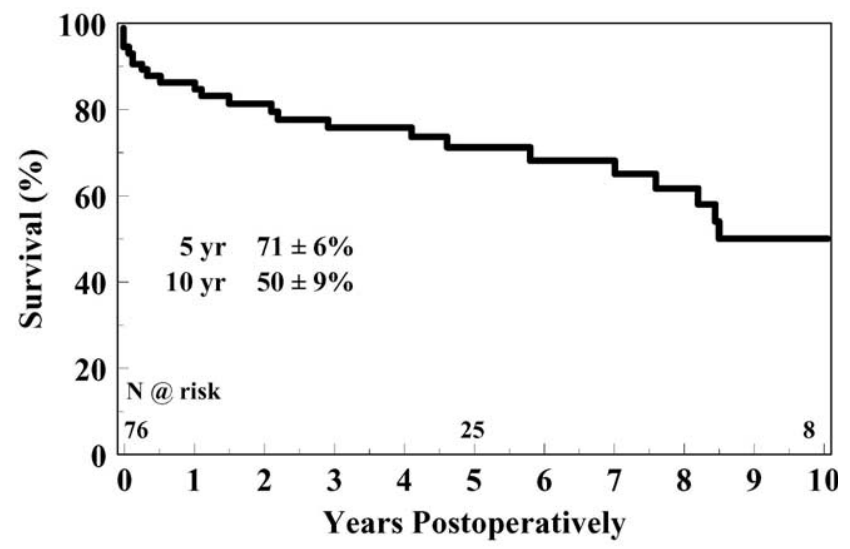

Figure 1. Long-term survival.

and to the superior aspect of the prosthetic mitral valve. The outer patch was used to close the dome of the left atrium and the inner patch to reconstruct the aortic root. An aortic prosthetic valve was implanted in the aortic position by securing it to the native aortic annulus and to the patch. In patients who underwent elective aortic and mitral valve replacement to treat patient-prosthesis mismatch, the intervalvular fibrous body was simply divided, and the reconstruction proceeded in the same manner to enlarge both annuli. A small number of patients required aortic root replacement with reimplantation of the coronary arteries.

Indications for the reconstruction of the intervalvular fibrous body were active infective endocarditis with abscess in 15 patients (20\%), extensive calcification in $24(32 \%)$, lack of fibrous tissue to secure the prosthetic valve because of multiple previous operations in $17(22 \%)$, and treatment or prevention of patient-prosthesis mismatch in 20 (26\%).

All patients had anticoagulation with warfarin sodium during the first 3 postoperative months if they had bioprosthetic aortic and mitral valves and permanently if they had mechanical valves or were in atrial fibrillation. Table 1 shows the operative data.

\section{Data Acquisition and Follow-up}

The ethics committee of our institution approved this study. The heart valve surgery database was reviewed for demographic, operative, perioperative, and outcome data. Follow-up was obtained through questionnaires, telephone interviews, and outpatient chart review. The longest follow-up was 162 months (mean of $47 \pm 47$ months), and follow-up was $100 \%$ complete. Most patients had multiple echocardiographic studies through the years, and every patient had at least one study.

\section{Statistical Analysis}

All data were analyzed with SAS version 8.1 (SAS Institute, Inc, Cary, NC). Continuous variables are reported as mean 


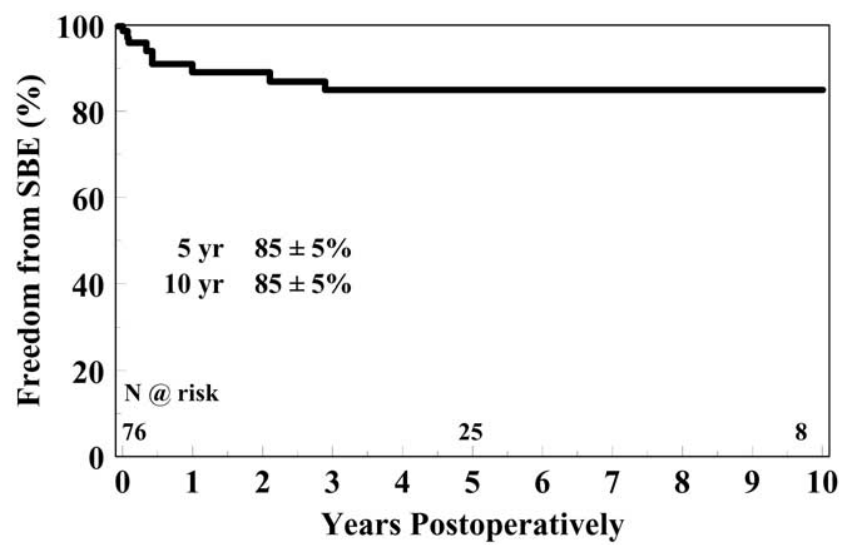

Figure 2. Freedom from prosthetic valve endocarditis (SBE).

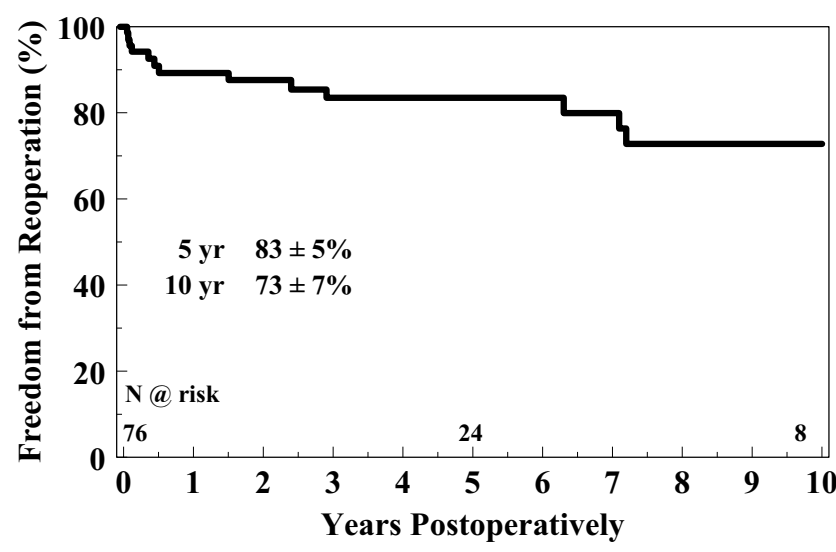

Figure 3. Freedom from any reoperation.

TABLE 2. Operative failures in reconstruction of the intervalvular fibrous body and reoperations

\begin{tabular}{|c|c|c|c|c|}
\hline Patient No. & Indication & $\begin{array}{l}\text { Indication for } \\
\text { reoperations }\end{array}$ & $\begin{array}{c}\text { Interval between } \\
\text { operations }\end{array}$ & Outcome \\
\hline 1 & Endocarditis & PVE & 3 wk & Survived \\
\hline 2 & Previous operations & PVE & $7 \mathrm{y}$ & Survived \\
\hline 3 & Extensive calcification & PVE & $3 y$ & Survived \\
\hline \multirow[t]{2}{*}{4} & Previous operations & PVE & 4 wk & Survived \\
\hline & & Patch tear & 7 y & Survived \\
\hline \multirow[t]{2}{*}{5} & Extensive calcification & PVE & 9 wk & Survived \\
\hline & & Patch tear & 7 y & Died* $^{*}$ \\
\hline 6 & Extensive calcification & PVE & $8 w k$ & Survived \\
\hline 7 & Small annuli & PVE & 24 wk & Died \\
\hline 8 & Previous operations & Valve degeneration & $11 y$ & Survived \\
\hline \multirow[t]{3}{*}{9} & Previous operations & Valve dehiscence & 4 wk & Survived \\
\hline & & Valve dehiscence & $4 \mathrm{~m}$ & Survived \\
\hline & & Patch dehiscence & 2 wk & Survived \\
\hline 10 & Previous operations & Patch tear & $2 y$ & Died \\
\hline 11 & Previous operations & Valve dehiscence & $6 y$ & Survived \\
\hline 12 & Previous operations & Paravalvular leak & 4 wk & Survived $†$ \\
\hline
\end{tabular}

$P V E$, Prosthetic valve endocarditis.

*This patient underwent heart transplant at another institution and died.

$\dagger$ This patient had repair of paravalvular dehiscence without taking down reconstructed annuli.

$\pm \mathrm{SD}$ in text and tables and as mean $\pm 1 \mathrm{SEM}$ in figures (unless otherwise noted). Categoric variables are reported as frequencies. Late outcomes were analyzed with the KaplanMeier method.

\section{Results}

\section{Operative Mortality and Morbidity}

There were 8 operative deaths (10\%): 3 of multiorgan failure, 2 of myocardial infarction, 1 of intracranial bleeding, and 2 from technical errors early on the series. Five patients $(7 \%)$ required reexploration of the mediastinum for bleeding, and 18 (24\%) patients had development of heart block requiring placement of a permanent pacemaker. Three patients had postoperative stroke; 1 died (intracranial bleed- ing), 1 was left with a residual neurologic deficit, and 1 recovered completely.

\section{Late Mortality and Morbidity}

There were 18 late deaths (24\%). The causes of late death were congestive heart failure in 6 patients, sudden death in 2 , infective endocarditis in 2 , myocardial infarction in 1 , paravalvular leak in 1 , septicemia in 1 , bowel ischemia in 1 , lung cancer in 1, complications after a heart transplant in 1 , and reoperations for prosthetic valve endocarditis in 1 and for patch dehiscence in 1 . The 10-year survival was $50 \% \pm$ 9\%, as illustrated in Figure 1. There were 3 strokes: 1 patient died, and 2 had complete neurologic recovery. The 10 -year freedom from stroke was $90 \% \pm 5 \%$. Seven pa- 
tients had prosthetic valve endocarditis develop, 5 early and 2 late. All of these patients underwent reoperation, and 1 died. The 10-year freedom from prosthetic valve endocarditis was $85 \% \pm 5 \%$ (Figure 2).

\section{Reoperations}

Twelve patients underwent 15 reoperations (Figure 3). Nine of the 12 patients who required reoperations had undergone circumferential reconstruction of the mitral annulus. Table 2 gives the indications for first reconstruction of the intervalvular fibrous body, the reasons for the first or subsequent reoperation, the time intervals between them, and the outcomes. The reasons for reoperation were prosthetic valve endocarditis in 7 patients, patch or prosthetic valve dehiscence in 7, and bioprosthetic valve failure in 1 . One patient with late patch or valve dehiscence had a heart transplant at another institution and died. We reoperated on the remaining 11 patients, 2 of whom died. Repeated reconstruction of the intervalvular fibrous body was performed in all but 1 patient, who had only repair of valve dehiscence.

One additional patient had late patch or valve dehiscence and was not offered reoperation because of prohibitively high operative risk related to comorbidities. This patient died 2 years later in congestive heart failure.

\section{Valve-Related Complications and Functional Class}

A total of 23 patients (30\%) had valve-related complications. The freedom from valve-related mortality and morbidity at 10 years was $60 \% \pm 7 \%$. At the last follow-up contact, 50 patients were alive. Among them 25 patients were in New York Heart Association functional class I, 13 were in class II, 11 were in class III, and 1 was in class IV. All 50 patients had normally functioning prosthetic valves at the latest echocardiographic study.

\section{Discussion}

A fibrous curtain that extends from the lateral to the medial fibrous trigones separates the aortic and mitral valves. This close relationship between the aortic and mitral valves limits the combined enlargement of both the aortic and mitral valve annuli to the area between the two trigones. Manouguian and associates ${ }^{7}$ described an operative procedure in a canine model whereby both the aortic and mitral annuli could be enlarged by cutting into the intervalvular fibrous body. This operation was performed in children with small annuli because of rheumatic valve disease. ${ }^{8,9}$ The indications were extended to the treatment of infective endocarditis with abscess of the intervalvular fibrous body, extensive calcification of the mitral annulus, and the lack of fibrous tissue to secure prosthetic valves because of multiple previous valve operations. ${ }^{1,3-6}$

We reported our initial experience with reconstruction of the intervalvular fibrous during aortic and mitral valve re- placement in $1997 .{ }^{1}$ The mortality and morbidity were high at $16 \%$, and we were concerned about the durability of the glutaraldehyde-treated bovine pericardium used for the reconstruction of the base of the heart. As the experience with the operation increased, the operative mortality decreased and has become more dependent on the pathology and patient's clinical presentation than on technical problems. This is a complex operation, however, and a sound knowledge of the anatomic relationships of the various components along the left atrioventricular groove and interventricular septum is necessary to perform it. After removal of the aortic and the mitral valves through the aortic root and dome of the left atrium, the left ventricular inflow and outflow tracts become a single orifice, which has to accommodate two prosthetic valves. Thus an excessively large prosthetic mitral valve fills the entire base of the ventricle and leaves no room for a prosthetic aortic valve. Conversely, if the heart is enlarged and a small mitral valve is implanted, it will deform the base of the heart. The size of the mitral valve prosthesis can be estimated by placing the valve manufacturer's sizer into the mitral annulus and observing how close it comes to the interventricular septum. The upper end of the valve sizer should be approximately $1 \mathrm{~cm}$ below the level of the aortic annulus. In addition, less than a third of its circumference should correspond to the distance between the lateral and medial fibrous trigones. Once a prosthetic valve is secured to the mitral annulus, the patch used to reconstruct the intervalvular fibrous body is as wide as the gap in between the lateral and medial fibrous trigones, usually 2 to $3 \mathrm{~cm}$. The areas where the patch joins the mitral annulus and the sewing ring of the prosthetic valve are probably the most important to prevent patch or valve dehiscence. This patch is then sutured to the aortic root, and a prosthetic aortic valve is secured to the native aortic annulus and the patch. The dome of the left atrium should be closed before implantation of the aortic valve.

Reconstructions that involve the posterior part of the mitral annulus are even more complex. ${ }^{5}$ Actually, 9 of 12 patients who needed reoperations had undergone reconstruction of the posterior mitral annulus in addition to reconstruction of the intervalvular fibrous body.

In cases of paravalvular abscess, we believe that radical resection of all infected tissues is more important than the type of patch material or valve used for the reconstruction. ${ }^{10}$ Most surgeons, however, consider aortic valve homografts ideally suited in these circumstances and also more resistant to reinfection. ${ }^{11}$ Aortic valve homograft with retained anterior leaflet of the mitral valve can be used to reconstruct the intervalvular fibrous body. We have used this technique in a few patients with aortic root abscess in whom the native mitral valve was repaired by replacing part of its base and the intervalvular fibrous body with the anterior leaflet of the 
donor, ${ }^{10}$ but we have never used it when the mitral valve was replaced.

Our series of 76 patients consisted of very sick patients who in addition to aortic and mitral valve dysfunction also had extensive calcification of the mitral annulus, annular abscess, small aortic and mitral annuli, or inadequate fibrous tissue to secure a new prosthetic valve because of at least two previous valve replacements. In the entire group, 55 patients had undergone one or more previous valve replacements.

The operative procedure failed in 13 of 68 patients who survived the initial operation. In 1 patient, the diagnosis of pericardial patch or valve dehiscence was made 11 years postoperatively, and reoperation was not offered because of the prohibitively high operative risk posed by comorbidities. This patient died of heart failure. The remaining 12 patients underwent a total of 15 reoperations. One patient received a heart transplant elsewhere for late patch or valve dehiscence and died. We performed the remaining 14 reoperations: 7 were for prosthetic valve endocarditis (5 early and 2 late), 6 for patch or valve dehiscence ( 3 early and 3 late), and 1 for late bioprosthetic valve failure.

There was a high rate of early infection, probably related to the amount of prosthetic material introduced at the time of surgery, the duration of the operative procedure, and the clinical status of the patients before surgery. There were also 3 early failures, which were related to technical errors. Indeed, this complication decreased as the experience increased. Another important point is that glutaraldehydepreserved bovine pericardium calcifies when used as a patch for reconstruction of the posterior mitral annulus and may rupture. Dacron polyester fabric graft is probably a better material for this purpose.

In summary, reconstruction of the intervalvular fibrous body during aortic and mitral valve replacement was a useful operative procedure in patients with complex heart valve pathology. The operative mortality was relatively low and decreased with experience. Infective endocarditis and technical failures were common early on but also decreased with experience. The long-term outcomes were satisfactory, but continuous surveillance of these patients was needed because of late patch or valve dehiscence.

\section{References}

1. David TE, Kuo J, Armstrong S. Aortic and mitral valve replacement with reconstruction of the intervalvular fibrous body. J Thorac Cardiovasc Surg. 1997;114:766-72.

2. Carpentier AF, Pellerin M, Fuzellier JF, Relland JY. Extensive calcification of the mitral valve anulus: pathology and surgical management. J Thorac Cardiovasc Surg. 1996;111:718-30.

3. Feindel CM, Tufail Z, David TE, Ivanov J, Armstrong S. Mitral valve surgery in patients with extensive calcification of the mitral annulus. J Thorac Cardiovasc Surg. 2003;126:777-82.
4. David TE, Feindel CM, Armstrong S, Sun Z. Reconstruction of the mitral anulus. A ten-year experience. J Thorac Cardiovasc Surg. 1995;110:1323-32.

5. d'Udekem Y, David TE, Feindel CM, Armstrong S, Sun Z. Long-term results of operation for paravalvular abscess. Ann Thorac Surg. 1996; 62:48-53.

6. Ergin MA, Raissi S, Follis F, Lansman SL, Griepp RB. Annular destruction in acute bacterial endocarditis. Surgical techniques to meet the challenge. J Thorac Cardiovasc Surg. 1989;97:755-63.

7. Manouguian S, Abu-Aishah N, Neitzel J. Patch enlargement of the aortic and mitral valve rings with aortic and mitral double valve replacement. J Thorac Cardiovasc Surg. 1979;78:394-401.

8. Manouguian S, Seybold-Epting W. Patch enlargement of the aortic valve ring by extending the aortic incision into the anterior mitral leaflet. J Thorac Cardiovasc Surg. 1979;78:402-12.

9. Rastan H, Atai M, Hadi H, Yazdanyar A. Enlargement of mitral valvular ring. New technique for double valve replacement in children or adults with small mitral anulus. J Thorac Cardiovasc Surg. 1980; 81:106-11.

10. David TE. Surgical management of aortic root abscess. J Cardiac Surg. 1997;12(2 Suppl):262-9.

11. Lytle BW, Sabik JF, Blackstone EH, Svensson LG, Pettersson GB, Cosgrove DM 3rd. Reoperative cryopreserved root and ascending aorta replacement for acute aortic prosthetic valve endocarditis. Ann Thorac Surg. 2002;74:S1754-9.

\section{Discussion}

Dr Kent W. Jones (Salt Lake City, Utah). I think this group in Toronto have been leaders in surgical treatment of valvular heart disease for a long time, and we are honored to have that group present a study at our meeting. Dr De Oliveira, I have a few questions. Have you considered in this group of patients using an aortic homograft with the retained anterior mitral leaflet to repair this area of the interfibrous body, rather than using the pericardial patch as you described?

Dr De Oliveira. No. The principles that we use to treat infective endocarditis are radical resection of all the infected tissue and all the inflamed tissue and then reconstruction with a patch. We do not use aortic homografts for reconstruction. For this patient population, who sometimes had multiple previous operations, you just need more patch material to be able to reconstruct the inflow and outflow of the ventricle, I believe.

Dr Jones. Have you used biologic glue for the anchoring of this pericardial patch, especially on the patients such as you described with the posterior mitral valve annulus that had to be decalcified and then covered with the pericardial patch? Did you use pericardial glue at all in that group?

Dr De Oliveira. The biologic glue is used rarely, and not to fix the patch. Occasionally when we finish the reconstruction of the dome of the left atrium, we just put some biologic glue over the suture line but not necessarily in the intervalvular fibrous area.

Dr Jones. In the article, but you didn't present it here, it appeared that about, as I recall, two thirds of the patients received mechanical prostheses and one third bioprostheses. What led to that decision?

Dr De Oliveira. That's a very good question. The bottom line is, I think, a decision made on the basis of what we know about the use of prosthetic and mechanical valves. 